\title{
Betonarme kolonların eşdeğer akma eğriliği için önerilen pratik bağıntıların irdelenmesi
}

\author{
Umut HASGÜL* \\ Balıkesir Üniversitesi Mühendislik Fakültesi İnşaat Mühendisliği Bölümü, Çağlş kampüsü, Balıkesir \\ Geliș Tarihi (Received Date): 21.11.2019 \\ Kabul Tarihi (Accepted Date): 19.12.2019
}

$\ddot{\mathbf{O z}}$

$\mathrm{Bu}$ çalışmada, yapı sistemlerinin şekildeğiştirme esaslı tasarımı ve değerlendirilmesi çerçevesinde, eşdeğer akma eğrilikleri için literatürde önerilen pratik yaklaşımların geçerliliği kare enkesitli betonarme kolonlar üzerinde teorik olarak incelenmiştir. Çalışma kapsamında, donatı akma dayanımı sabit tutularak enkesit boyutu, normal kuvvet düzeyi, boyuna donatı oranı ve beton basınç dayanımının parametrik olarak değiştirildiği 1500'ün üzerindeki hesap modeli için moment - eğrilik analizleri gerçekleştirilmiştir. Bu analiz sonuçları referans alınarak, ilgili bağıntıların hangi oranda doğru sonuç verdiği geniş bir çerçevede değerlendirilmiştir. Incelenen kolon enkesitlerine ait eşdeğer akma ĕgriliklerinin belirlenmesinde normal kuvvetin düzeyine bağlı olarak, $P / A_{g} f_{c}{ }^{\prime}<0.3$ için donatı çeliğinin akması, $P / A_{g} f_{c}{ }^{\prime}=0.3$ için donatı çeliğinin akmast velveya betonun ezilmesi, $P / A_{g} f_{c}{ }^{\prime}>0.3$ için ise betonun ezilmesi hakim olmuştur. Pratik bağıntılardan elde edilen akma eğrilikleri için boyuna donatı oranı ve beton basınç dayanımının bağımsız etkileri sınırlı iken, normal kuvvet düzeyi ile birlikte olan birleşik etkileri bu parametreleri önemli hale getirmiştir.

Anahtar kelimeler: Eşdeğer akma ĕ̆riliği, betonarme kolon, moment - ĕgrilik analizi, normal kuvvet düzeyi, boyuna donatı oranı, beton basınç dayanımı.

\section{Investigation of practical equations for equivalent yield curvature of reinforcement concrete columns}

\begin{abstract}
In this study, the usability of practical approaches proposed for equivalent yield curvature on reinforcement concrete columns with the square cross-section was numerically investigated in the framework of deformation based design and assessment
\end{abstract}

\footnotetext{
*Umut HASGÜL, hasgul@balikesir.edu.tr, http://orcid.org/0000-0002-9358-3369
} 
of structural systems. In this context, the moment - curvature analyses on the column models more than 1500, in which the axial load level, cross-section dimension, longitudinal reinforcement ratio and concrete compression strength were modified parametrically, were conducted for the constant yield strength. Based on the analysis results, in what proportion the related equations give results was discussed comprehensively. Depending on the axial load levels of $P / A_{g} f_{c}{ }^{\prime}<0.3, P / A_{g} f_{c}{ }^{\prime}=0.3$ and $P / A_{g} f_{c}{ }^{\prime}>0.3$ for the considered columns, the yielding of reinforcement, yielding of reinforcement and/or concrete crushing, concrete crushing governed the formation of yield curvatures, respectively. It can be deduced that while the independent effects with regard to the longitudinal reinforcement ratio and concrete compressive strength for the equivalent yield curvatures calculated by the practical approaches remained in minimal levels, the combined effects of them with the axial load level make these parameters become important these parameters.

Keywords: Equivalent yield curvature, reinforced concrete column, moment - curvature analysis, axial load level, reinforcement ratio, concrete compression strength.

\section{Giriş}

Deprem etkisindeki yapı sistemlerinin yapısal ve yapısal olmayan elemanlarında oluşan hasar durumu, doğrudan yerdeğiştirme ve şekildeğiştirme büyüklükleri ile ilişkili olduğundan (birim şekildeğiştirme, plastik dönme, öteleme gibi), bunu kontrol etmek için en etkin parametrenin dayanımdan ziyade yerdeğiştirmeler olduğu bilinmektedir. Belirli bir deprem seviyesi/seviyeleri altında doğrusal olmayan teoriyi esas alan statik/dinamik analiz yöntemleri kullanılarak bu davranış taleplerinin belirlenmesinde en önemli parametrelerden biri sünekliktir. Bilindiği üzere, kesit, eleman ve sistem bazında yerdeğiştirme, eğrilik ve öteleme sünekliklerinin hesabı için akma eğriliğinin ve buna bağlı olarak akma yerdeğiştirmesinin gerçekçi belirlenmesi yapıların tasarımında ve değerlendirilmesinde önem arz etmektedir.

Pek çok yönetmelikte farklı eleman türleri için eğilme rijitliğini azaltan çarpanlar öngörülmektedir [1-5]. Örneğin, kirişler için $0.35^{\prime}$ 'lik bir azaltma çarpanı uygulanırken, kolonlarda normal kuvvet düzeyine bağlı olarak 0.4 ile 0.7 arasında değişen çarpanlar uygulanmaktadır. $\mathrm{Bu}$ yaklaşım, enkesit rijitliklerinin belirlenmesinde önemli bir iyileştirme olmasına karşın elemandaki normal kuvvet, boyuna donatı oranı ve malzeme karakteristikleri gibi muhtemel etkileri ihmal etmektedir. Mevcut kuvvet esasl yönetmeliklerde önerilen sabit etkin rijitlik ifadelerinin, tasarımda güvenli tarafta kalacak şekilde eleman rijitliklerini fazla belirlemekle birlikte şekildeğiştime esaslı sismik deformasyon taleplerini belirlemede yetersiz kalabildiği belirtilmektedir [6]. Eğilme rijitliği için uygulanan bu yaklaşım, etkin rijitliğin dayanımdan bağımsız olarak sabit olduğunu ve elemanın eğilme kapasitesinin artması ile değişmediğini göstermektedir. $\mathrm{Bu}$ sonuç, akma yerdeğiştirmesinin doğrudan dayanımla orantılı olduğunu ortaya çıkarmaktadır (Şekil 1a). Kuvvet esaslı tasarım yaklaşımında yapılan bu kabulün geçersiz olduğu pek çok çalışmada belirtilmektedir [7-10]. Tasarım yönetmeliklerinde belirtilen sınırlar içerisinde betonarme kolonlar üzerinde yapılan parametrik incelemeler, akma eğriliğinin büyük ölçüde enkesit karakteristiğine bağımlı olduğunu ve dayanımdan bağımsız olduğunu göstermiştir (Şekil 1b). Bununla birlikte, moment-eğrilik davranışının iki doğru parçası ile idealleştirilmesiyle elde edilen eşde ğer akma ĕgriliğinin $\left(\phi_{y}\right)$, normal kuvvet düzeyi ve boyuna donatı oranının geniş bir bölgesi için sabit olduğu ifade edilmektedir [7,8,10-12]. 
Priestley vd. tarafından, betonarme çerçeve binaların dikdörtgen enkesitli kolonlarında etkin eğilme rijitliği ve akma eğriliğine etkileyen parametreler irdelenmiștir $[8,10]$. Enkesit boyutu, kabuk betonu kalınlığı, beton basınç dayanımı ve donatı akma dayanımı sabit tutularak normal kuvvet düzeyinin $\left(P / A_{g} f_{c}^{\prime}=0-0.4\right)$ ve donatı oranının farklı değerleri $\left(\rho_{l}=\% 0.5-4.0\right)$ için moment-eğrilik analizleri yapılmıştır. Elde edilen sonuçlar, enkesite ait moment taşıma kapasitesinin belirlenmesinde normal kuvvet düzeyi ve donatı oranının, beklenildiği gibi, önemli etkisinin olduğunu göstermiştir (Şekil 2a). Bununla birlikte, boyutsuz akma eğriliklerinin $\left(\phi_{y} h / \varepsilon_{y}\right)$ bu büyüklüklere ait değişimlerden çok az oranda etkilendiği belirlenmiş ve ortalama 2.10 değeri önerilmiştir. Bu değer kullanılarak eşdeğer akma eğrilikleri $\pm \% 10$ 'luk bir bant içinde belirlenebilmiştir (Şekil 2b). Burada, $P, A_{g}$ ve $f_{c}^{\prime}$ sirasıyla normal kuvveti, brüt enkesit alanını ve karakteristik beton basınç dayanımını gösterirken, $\phi_{y}, h$ ve $\varepsilon_{y}$ sırasıyla eşdeğer akma eğriliğini, enkesit yüksekliğini ve boyuna donatının akmadaki birim şekildeğiştirmesini ifade etmektedir.

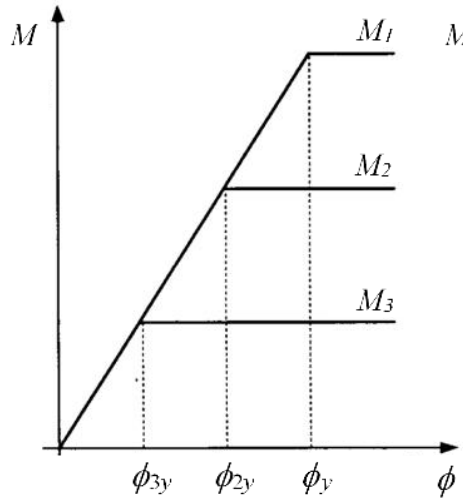

a) Tasarım yaklaşımı (sabit rijitlik)

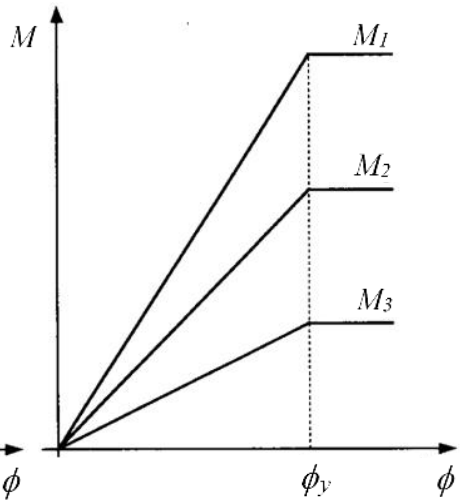

b) Gerçek davranış (sabit akma eğriliği)

Şekil 1. Moment-eğrilik davranışında dayanımın etkisi [7,8].
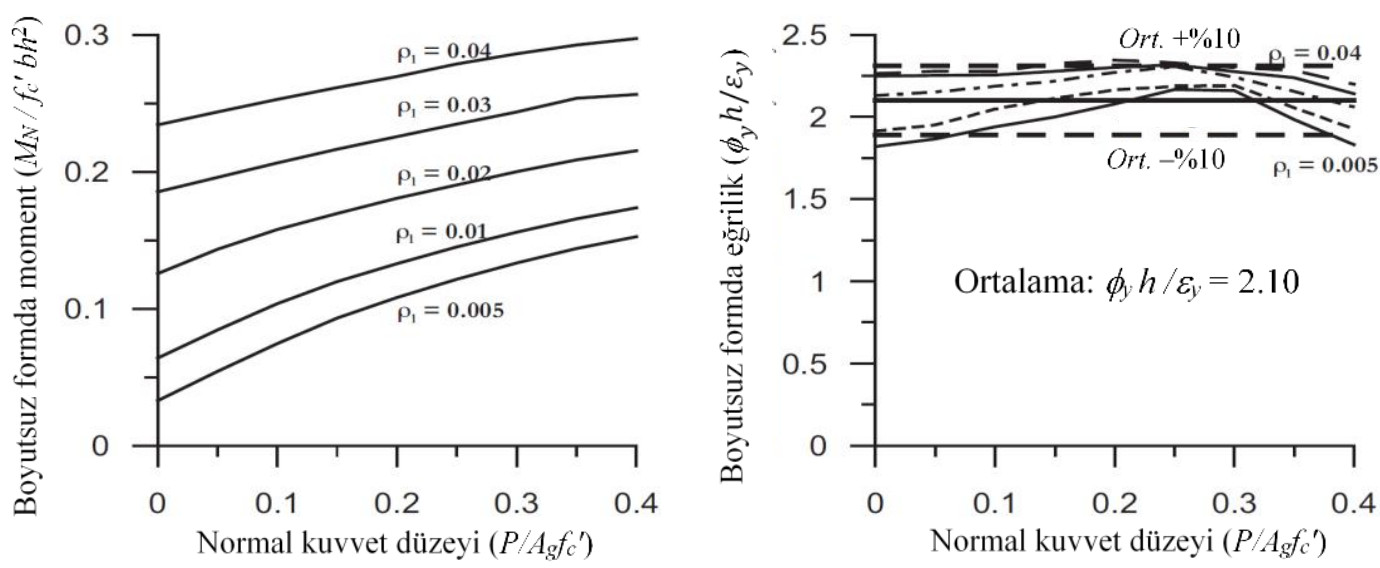

Şekil 2. Boyutsuz formda a) moment taşıma kapasitesi ve b) eşdeğer akma eğriliği [10].

$\mathrm{Bu}$ çalışmalar neticesinde, farklı enkesit geometrileri için eşdeğer akma eğriliğinin pratik hesabına yönelik (1a-d) bağıntıları önerilmiştir [7,8,10,12,13].

$\phi_{y}=2.10 \frac{\varepsilon_{y}}{h_{c}} \quad$ (Betonarme dikdörtgen kolonlar için) 
$\phi_{y}=2.25 \frac{\varepsilon_{y}}{D} \quad$ (Betonarme dairesel kolonlar için)

$\phi_{y}=2.00 \frac{\varepsilon_{y}}{l_{w}} \quad$ (Betonarme dikdörtgen perdeler için)

$\phi_{y}=1.70 \frac{\varepsilon_{y}}{h_{b}} \quad$ (Betonarme T enkesitler için)

Burada; $h_{c}, D, l_{w}$ ve $h_{b}$ sirasiyla, dikdörtgen kolonun, dairesel kolonun, perdenin ve $T$ enkesitli betonarme elemanın enkesit yüksekliğini göstermektedir.

Yerdeğiştirmeyi esas alan sismik tasarım yöntemlerinde akma yerdeğiştirmesinin daha gerçekçi belirlenmesi için dairesel ve dikdörtgen enkesitli betonarme kolonların eşdeğer akma eğrilikleri Montes ve Aschleim tarafindan incelenmiştir [14]. Kolon enkesitlerinin enkesit yüksekliği, normal kuvvet düzeyi, boyuna donatı oranı, donatı akma dayanımı ve beton basınç dayanımı parametrik değiştirilerek moment - eğrilik analizleri yapılmıştır. İncelenen parametreler çerçevesinde, akma eğriliğinin pratik hesabı için (2a-b) bağıntıları önerilmiştir. Bu yaklaşım, [8,13]'deki (1a) bağıntısını esas almakla birlikte, normal kuvvet düzeyinin etkisini de içermektedir [14]. (2a-b) bağıntılarında; $\varepsilon_{y}$ donatının akmadaki birim şekildeğiştirmesini, $d$ enkesitin etkin yüksekliğini, $P / A_{g} f^{\prime}{ }^{\prime} d$ ise normal kuvvet düzeyini göstermektedir.

$$
\begin{array}{ll}
\phi_{y}=\frac{\varepsilon_{y}}{d}\left[2.3-\left(0.6-2.5 \frac{P}{A_{g} f_{c d}}\right)^{2}\right] & (\mathrm{B}-400 \text { donatı çeliği için }) \\
\phi_{y}=\frac{\varepsilon_{y}}{d}\left[2.2-\left(0.6-2.5 \frac{P}{A_{g} f_{c d}}\right)^{2}\right] & \text { (B-500 donatı çeliği için })
\end{array}
$$

Betonarme perde yapıların sünek tasarımında akma yerdeğiştirmelerin hesabı için eşdeğer akma eğriliği Tjhin vd. tarafından nümerik olarak araştııılmıştır [15]. Normal kuvvet düzeyi, boyuna donatı oranı, gövde donatısı oranı, beton basınç dayanımı ve donatının akma dayanımını içeren moment - eğrilik analizleri sonucunda, eşdeğer akma eğriliğinin pratik hesabı için (3) bağıntısı önerilmiştir. Normal kuvvet düzeyinin düşük düzeyleri için $\left(P / f_{c}^{\prime} A_{w}=0-0.2\right)$ akma eğriliklerinin $\% 5-\% 10$ arasında hata oranları ile elde edilebildiğ $i$ belirtilmiştir.

$\kappa_{\phi}=1.8 \varepsilon_{y}+0.0045 \frac{P}{f_{c}{ }^{\prime} A_{w}}$

Literatürde betonarme kolonlar üzerinde yapılan çalışmalar sonucunda, enkesit boyutu, normal kuvvet düzeyi, boyuna donatı oranı ile malzemeye ait karakteristik dayanımlarının eşdeğer akma eğriliğine ve buna bağlı olarak, akma yerdeğiştirmesi ve yerdeğiştirme sünekliğini önemli oranda etkileyebileceğini göstermiştir. Buna karşın, akma eğriliğinin pratik hesabı için önerilen ampirik bağıntılarda, genel olarak, sadece enkesit yüksekliği ile donatının akmadaki birim şekildeğiştirmesinin gözönüne aldığı, diğer parametrelere ait bağımsız ve/veya birleşik etkilerinin ise ihmal edildiği görülmektedir.

$\mathrm{Bu}$ çalışmada, yapı sistemlerinin şekildeğiştirme esaslı tasarımı ve değerlendirilmesi çerçevesinde, betonarme kolonların eşdeğer akma eğrilikleri için literatürde önerilen pratik yaklaşımların geçerliliği kare enkesitler üzerinde teorik olarak incelenmiştir. Çalışma kapsamında, donatı akma dayanımı sabit tutularak enkesit boyutu, normal kuvvet düzeyi, boyuna donatı oranı ve beton basınç dayanımının parametrik olarak değiştirildiği 1500 'ün üzerindeki hesap modeli için moment - eğrilik analizleri gerçekleştirilmiştir. Bu 
analiz sonuçları referans alınarak, ilgili bağıntıların hangi oranda doğru sonuç verdiği geniş bir çerçevede değerlendirilmiştir.

\section{Betonarme kolonlar üzerinde sayısal incelemeler}

\subsection{Kolon enkesitlerinin özellikleri}

Sayısal incelemeler kapsamında, betonarme kolonların moment - eğrilik analizleri ile eşdeğer akma eğriliğine ait ampirik bağıntıları uygulamak amacıyla, 7 kare enkesit boyutu $(b x h)$ ile 8 boyuna donatı oranı $\left(\rho_{l}\right)$ sistematik değiştirilerek toplam 56 adet hesap modeli oluşturulmuş ve daha sonra, normal kuvvet düzeyi $\left(P / A_{g} f_{c}^{\prime}\right)$ ve beton basınç dayanımları $\left(f_{c}^{\prime}\right)$ değiştirilerek çok sayıda hesap modeli türetilmiştir (Şekil 3 ve Tablo 1). Kolon enkesitlerine ait eşdeğer akma eğrilikleri, donatı akma dayanımı $\left(f_{y}\right)$ ile doğrudan değiştiğinden, diğer parametrelerdeki değişimlerin bağımsız ve/veya birleşik etkilerini irdelemek amaciyla donatıya akma dayanımı ve kabuk betonu kalınlığı oranı sabit tutulmuştur (Tablo 1).

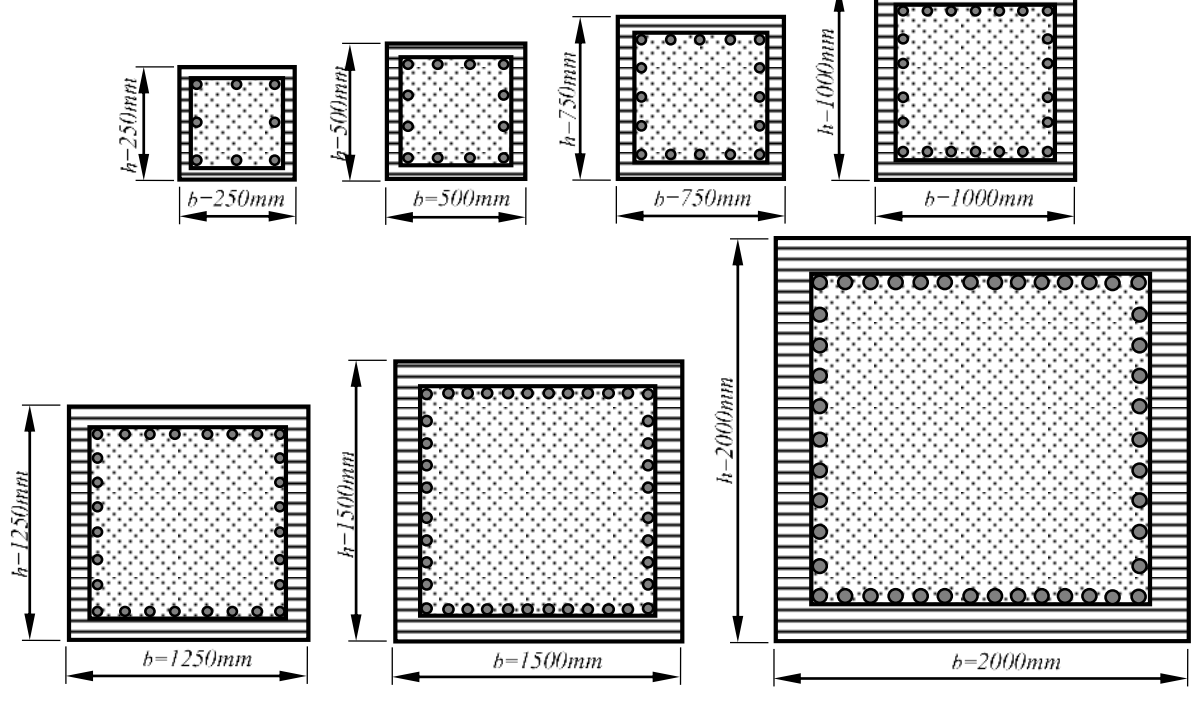

Şekil 3. İncelenen betonarme kolon enkesitleri.

Tablo 1. Kolon hesap modellerine ait parametrelerin özeti.

\begin{tabular}{cccccc}
\hline $\begin{array}{c}\text { Enkesit } \\
\text { boyutlar1 } \\
b \times h(\mathrm{~cm})\end{array}$ & $\begin{array}{c}\text { Boyuna } \\
\text { donatı oran1 } \\
\rho_{l}(\%)\end{array}$ & $\begin{array}{c}\text { Normal kuvvet } \\
\text { düzeyi } \\
\left(P / A_{g} f_{c}\right)\end{array}$ & $\begin{array}{c}\text { Beton basınç } \\
\text { dayanım1 } \\
f_{c}^{\prime}(\mathrm{MPa})\end{array}$ & $\begin{array}{c}\text { Donat1 akma } \\
\text { dayanım1 } \\
f_{y}(\mathrm{MPa})\end{array}$ & $\begin{array}{c}\text { Kabuk } \\
\text { betonu oranı } \\
\left(A_{c} / A_{g}\right)\end{array}$ \\
\hline & 0.5 & 0 & 20 & & \\
& 1.0 & 0.1 & 30 & & \\
$25 \times 25$ & 1.5 & 0.2 & 40 & & \\
$50 \times 50$ & 2.0 & 0.3 & 50 & & \\
$75 \times 75$ & 2.5 & 0.4 & 60 & 410 & \\
$100 \times 100$ & 3.0 & 0.5 & & & \\
$125 \times 125$ & 4.5 & & & & \\
$150 \times 150$ & & & & & \\
$200 \times 200$ & & & & & \\
\hline
\end{tabular}

\subsection{Varsayımlar}

Betonarme kolon enkesitlerinin moment-eğrilik analizlerinde yapılan başlıca varsayımlar aşağıda özetlenmiştir. 
- Dik kesit şekildeğiştirdikten sonrada düzlem kalmaktadır.

- Çatlamış betonun çekme dayanımı ihmal edilmiştir.

- Beton ve donatı çeliği arasında tam aderans bulunmaktadır.

- Malzemenin gerilme - şekildeğiştirme bağıntısı; sargısız kabuk betonu ve sargılı göbek betonu için Mander vd. [16,17]'de önerilen beton modeli, donatı çeliği için ise King vd. [18]'deki model esas alınmıştır (Şekil 4).

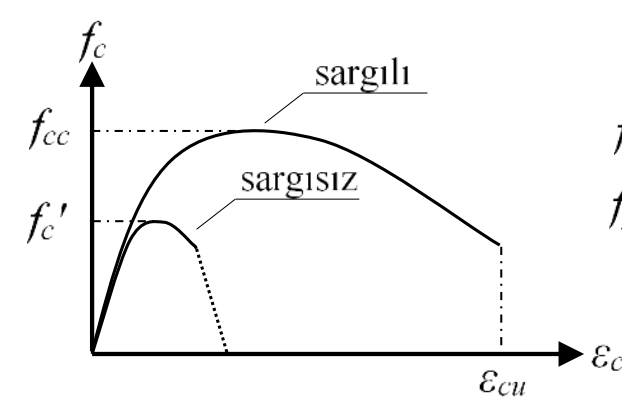

Sargılı ve sargisız beton modelleri

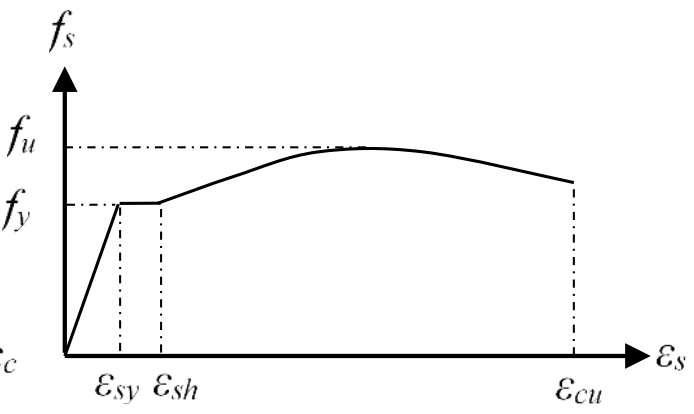

Donatı çeliği modeli

Şekil 4. Beton ve donatı için gerilme - şekildeğiştirme bağıntıları.

\subsection{Moment - ĕgrilik analizleri}

Betonarme bir enkesitin çatlama, elastik ve plastik bölgelerdeki davranışının belirlenmesi, akma ve taşıma gücü arasındaki herhangi bir sınır durumda (kullanılabilirlik, hasar kontrolü, can güvenliği vb.) şekildeğiştirme durumunun belirlenmesi ve ayrıca, elemanın kuvvet - deformasyon - süneklik ilişkilerinin belirlenmesi amacıyla moment - eğrilik analizine ihtiyaç duyulur. Bununla birlikte, öngörülen sınır durum düzeyinde donatıda burkulmanın olup olmadığı, kesme kapasitesinin aşılıp aşılmadığını kontrol etmek için de moment - eğrilik analizinden yararlanılmaktadır.

Çalışmada, eşdeğer akma eğriliklerini doğrudan veya dolaylı etkileyebileceği düşünülen farklı parametreler (normal kuvvet düzeyi $-P / A_{g} f_{c}^{\prime}$, enkesit boyutu - $b x h$, boyuna donatı oran $1-\rho_{1}$ ve beton basınç dayanımı $-f_{c}^{\prime}$ ) gözönünde bulundurularak kolon enkesitlerinin moment - eğrilik analizleri yapılmıştır. Analizlerde Cumbia bilgisayar programından yararlanılmıştır [19]. Cumbia, dikdörtgen ve dairesel betonarme enkesitler için kabuk ve göbek betonunu bağımsız dilimlere ayırarak doğrusal olmayan kesit analizlerini yapabilmektedir. Ayrıca, herhangi bir sınır duruma karşılık gelen kuvvet - deformasyon - yerdeğiştirme - süneklik ilişkileri ayrıntılı olarak belirlenebilmektedir.

\subsubsection{Eşdĕger akma ĕgriliğinin hesabı}

Enkesit bazındaki sünekliğin hesabı için moment - eğrilik davranışı, elastik ve plastik kısım olmak üzere iki doğru parçası şeklinde idealleştirilebilir. Şekil 5'den görüleceği üzere, idealleştirilmiş grafiğinin elastik kısmını oluşturan doğru, başlangıçtan ilk akma noktası $B$ 'ye kadar $\left(\phi_{y}^{\prime}, M_{y}^{\prime}\right)$ birleştirilir. Daha sonra, bu doğru parçası nominal moment değerine ( $C$ noktasına) kadar ekstrapole edilerek, idealleştirilmiş davranışa ait eşdeğer akma eğriliği $\left(\phi_{y}\right)$ elde edilir. Böylece, eşdeğer akma noktası $\left(\phi_{y}, M_{N}\right)$ ve taşıma gücüne karşı gelen $D$ noktası $\left(\phi_{u}, M_{u}\right)$ birleştirilerek idealleştirilmiş grafiğin plastik kısmı belirlenir (Şekil 5). İdealleştirilmiş moment - eğrilik grafiğine ait eşdeğer akma eğriliği (4) bağıntısı ile hesaplanabilir [10].

$\phi_{y}=\frac{M_{N}}{M_{y}{ }^{\prime}} \phi_{y}{ }^{\prime}$ 


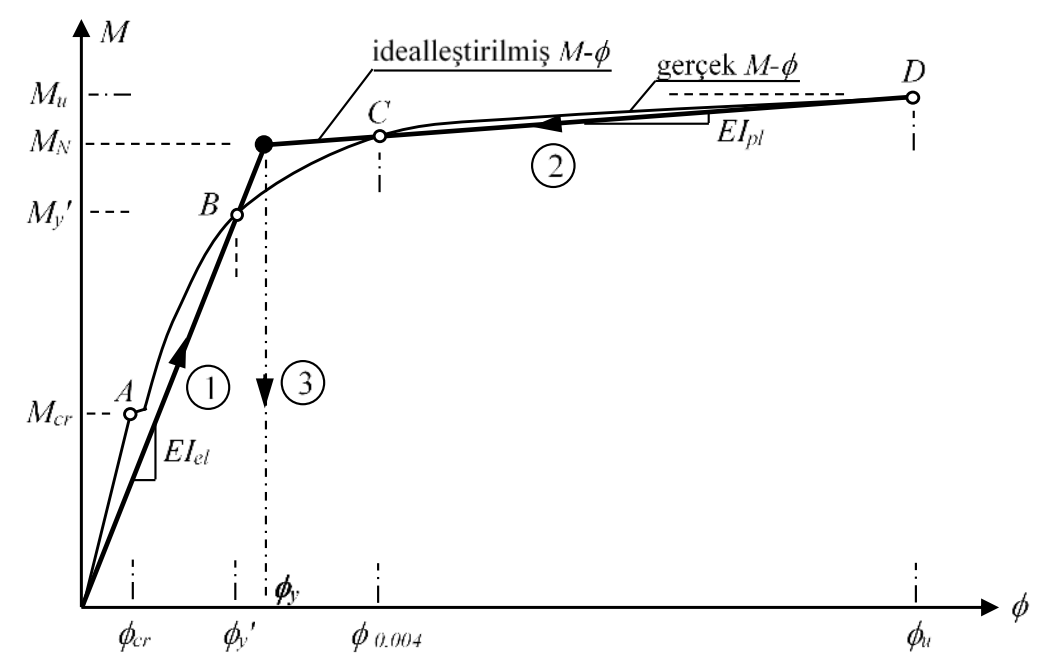

Şekil 5. Tipik bir moment - eğrilik grafiği ve iki doğru parçalı idealleştirilmesi.

\subsection{Eşdĕger akma ĕgriliği için önerilen pratik yaklaşımların değgerlendirilmesi}

Dikdörtgen enkesitli betonarme elemanlara ait eşdeğer akma eğriliklerinin pratik hesabı için literatürde üç güncel yaklaşım bulunmaktadır. Esasları yukarıda verilen bu yaklaşımlardan en yaygın olanı Priestley tarafindan [8,13]'de önerilen (1a) bağıntısıdır. $\mathrm{Bu}$ yaklaşımda, akma durumunun belirlenmesinde donatı çeliğinin hakim olduğu varsayımı yapılmakta $\left(\varepsilon_{s}=\varepsilon_{s y}\right)$ ve eşdeğer akma eğriliği $\left(\phi_{y}\right)$, enkesit yüksekliği $(h)$ ve donatının akmadaki birim şekildeğiştirmesine $\left(\varepsilon_{s y}\right)$ bağlı olarak hesaplanmaktadır. Önerilen bağıntıda enkesitteki normal kuvvet düzeyi, boyuna donatı oranı ve beton basınç dayanımı gibi parametrelerin etkisi ihmal edilmekle birlikte, akma eğriliklerinin $\pm \% 10$ 'lik bir tölerans içerisinde kaldığı belirtilmektedir [8,10,13]. Literatürdeki diğer iki ayrı çalışmada [14,15], akma eğriliklerinin pratik hesabı için (1a) bağıntısının ana çerçevesi korunarak ve normal kuvvet düzeyinin etkisi de ilave edilerek iyileştirilmeye çalış1lmıştır. Buna karşın, boyuna donatı oranı ve beton basınç dayanımlarındaki değişimlerin etkisi ihmal edilmiştir.

Çalışmada incelenen kolon enkesitlerine, bu yaklaşımlar uygulanmış ve moment - eğrilik analizlerinden elde edilen sonuçlar referans alınarak değerlendirilmiştir. Burada, [15]'de önerilen (3) bağıntısı, esasen perde elemanların tasarımı için önerildiğinden ve normal kuvvetin sadece düşük düzeylerinde $\left(P / A_{w} f_{c}^{\prime} \leq 0.2\right)$ geçerli olduğundan sayısal incelemelerde gözönüne alınamamıştır. Çalışmada gözönüne alınan parametrelerin eşdeğer akma eğriliğine bağlı değişimleri ile karşılaştırmalar sabit bir donatı akma dayanımı için yapılmıştır. Daha düşük veya yüksek dayanımlı donatılar kullanılması halinde, davranışa ait genel karakteristiğin değişmeyeceği ve akma dayanımı arttıkça akma eğriliğinin artacağı bilinmektedir [8,10,11,14]. Çalışmada ele alınan her bir parametredeki değişimin akma eğriliği üzerindeki etkisi, istatiksel olarak hesaplanan ortanca (median) değerler esas alınarak değerlendirilmiştir.

\subsubsection{Enkesit yüksekliğinin değişimi bakımından sonuçların irdelenmesi}

$P / A_{g} f_{c}{ }^{\prime}=0-0.5$ arasında incelenen 6 normal kuvvet düzeyi için moment - eğrilik analizlerinden ve pratik yaklaşımlardan elde edilen eşdeğer akma eğriliklerinin enkesit yüksekliği ile değişimleri Şekil 6'da verilmiştir. Moment - eğrilik analizleri sonucunda, akma eğrilikleri $h \leq 125^{\mathrm{cm}}$ e kadar hızla azalan yönde bir karakteristik göstermekle birlikte, enkesit yüksekliğinin artan değerleri için değiş̧imler sınırlı kalmaktadır (Şekil 6). Bununla birlikte, ampirik bağıntılara ait sonuçlar incelendiğinde; 
Priestley tarafından önerilen (1a) bağıntısı, enküçük kolon enkesiti dışındaki her enkesit boyutunda birbirine yakın rölatif farklar ile eşdeğer akma eğriliklerini belirlemekle birlikte, normal kuvvet düzeyine bağlı olarak oluşan bu farkların eşit oranda azaldığ ya da arttığı görülmüştür (Şekil 6). Bununla birlikte, ilgili bağıntıya ait en büyük rölatif fark $P / A_{g} f_{c}{ }^{\prime}=0.2$ için oluşmuştur. Akma durumunun belirlenmesinde donatı çeliğinin hakim olduğu $P / A_{g} f_{c}^{\prime} \leq 0.3$ için hesaplanan rölatif farklar $-\% 14.1 \sim+\% 1.5$ arasında değişmekle birlikte, akma eğrilikleri ortalama $\% 7$ hata ile belirlenebilmektedir. Normal kuvvetin ilerleyen düzeyleri için bu farklar artan yöne geçmektedir. Çalışmada gözönüne alınan en büyük normal kuvvet düzeyi $\left(P / A_{g} f_{c}{ }^{\prime}=0.5\right)$ için, akma eğrilikleri arasındaki farkların +\%13.8'e ulaşabildiği belirlenmiştir.

Montes ve Aschleim tarafından önerilen (2a) bağıntısı kullanıldığında, gözönüne alınan her normal kuvvet düzeyi ve enkesit yüksekliği için hesaplanan eşdeğer akma eğrilikleri, moment - eğrilik analiz sonuçları ile oldukça uyumludur (Şekil 6). $P / A_{g} f_{c}{ }^{\prime} \leq 0.3$ için, -\%11.6 +\%6.5 arasında değişen farklar oluşmasına karşın, farklı enkesit yüksekliklerine ait ortalama fark oldukça düşüktür $(\% 0.2) . P / A_{g} f_{c}^{\prime}=0.4$ ve 0.5 düzeyleri için bu farklar ortalama olarak, sırasıyla, $+\% 6.4$ ve $+\% 4.4$ oranındadır. Burada, ilgili bağıntıya ait en büyük rölatif fark, en küçük yüksekliğe sahip $\left(b x h=25 \times 25^{\mathrm{cm}}\right)$ ve normal kuvvetsiz $\left(P / A_{g} f_{c}^{\prime}=0\right)$ kolon enkesitinde oluşmuştur.
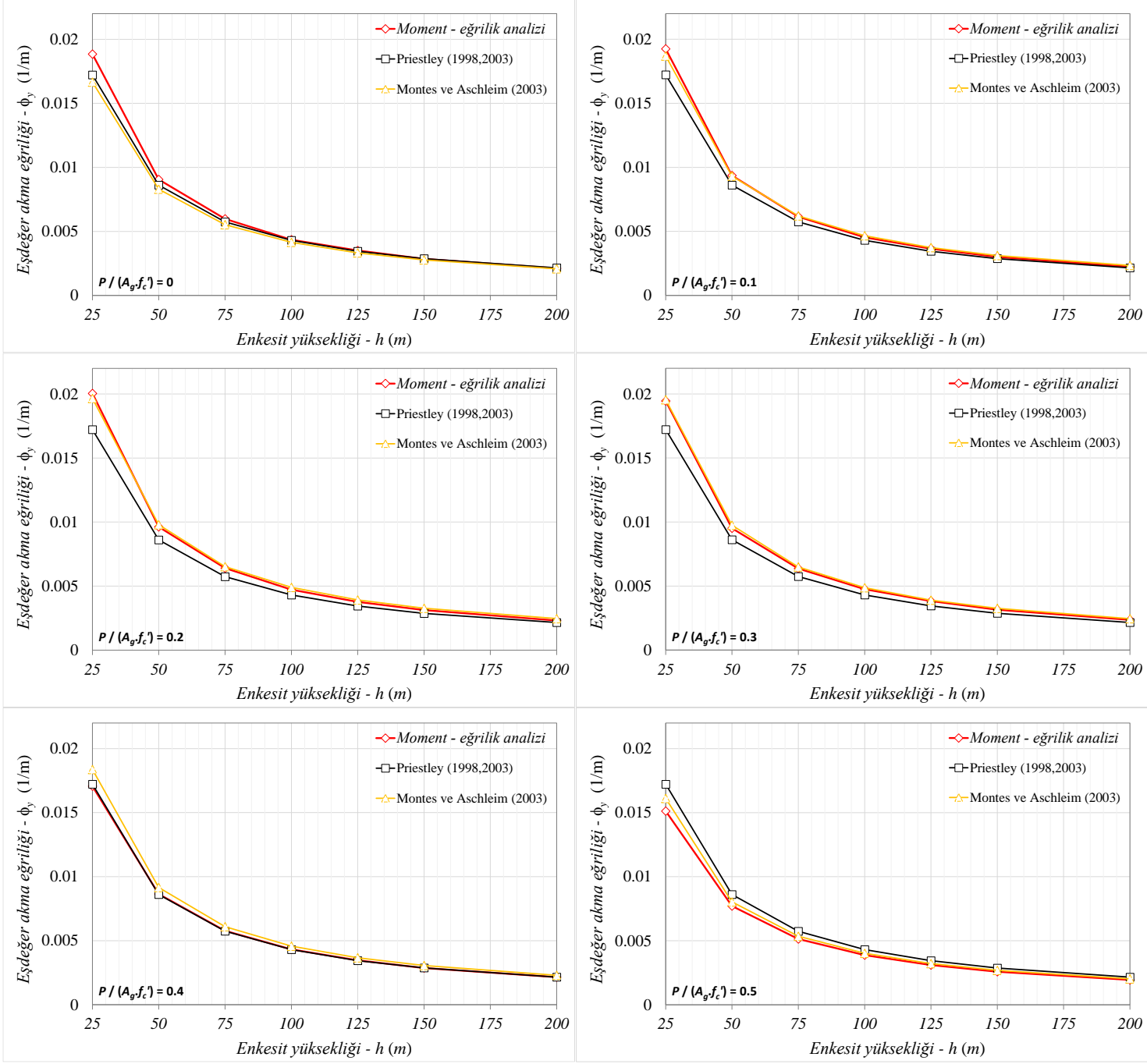

Şekil 6. Enkesit yüksekliğinin farklı değerleri için akma eğriliklerinin karşılaştırılması. 


\subsubsection{Boyuna donatı oranındaki değişim bakımından sonuçların irdelenmesi}

İncelenen kolon enkesitlerinin moment - eğrilik analizlerinden ve pratik yaklaşımlardan elde edilen eşdeğer akma eğriliklerinin boyuna donatı oranı ile değişimleri farklı normal kuvvet düzeyleri için Şekil 7'de verilmiștir. Moment - eğrilik analizleri sonucunda, donatı oranı arttıkça akma eğriliklerinin bir miktar arttığı, buna karşın ampirik bağıntıların bu değişimi belirlemede yetersiz kalabildikleri görülmüştür. İlgili bağıntılara ait sonuçlar incelendiğinde;

$\rho_{l}=\% 0.5 \sim 4.0$ arasında gözönüne alınan 8 boyuna donatı oranı için (1a) bağıntısı ile hesaplanan eşdeğer akma eğriliklerinin, normal kuvvet düzeyine bağlı olarak azalan veya artan yönde olabildiği görülmüştür (Şekil 7). Burada, $P / A_{g} f_{c}^{\prime} \leq 0.3$ için hesaplanan akma eğrilikleri -\%12.7'ye ulaşan oranlarda daha az iken $\left(\rho_{l}=\% 0.5\right.$ ve 1.0 dişında), beton ezilmesinin hakim olduğu $P / A_{g} f_{c}^{\prime}>0.3$ için hesaplanan farkların artarak pozitif yöne geçtiği belirlenmiştir. Bu bölgede, donatı oranı arttıkça bu farkların azalan yönde bir karakteristik göstermektedir (Şekil 7). $P / A_{g} f_{c}{ }^{\prime}=0.4$ ve 0.5 düzeyleri için akma eğriliklerine ait rölatif farklar sırasıyla, $-\% 7.3 \sim+\% 13.7$ ve $-\% 0.1 \sim+\% 30.5$ arasında değişmekle birlikte, hesaplanan ortalama hata oranları $\% 1$ ve $\% 12.5$ seviyelerindedir.
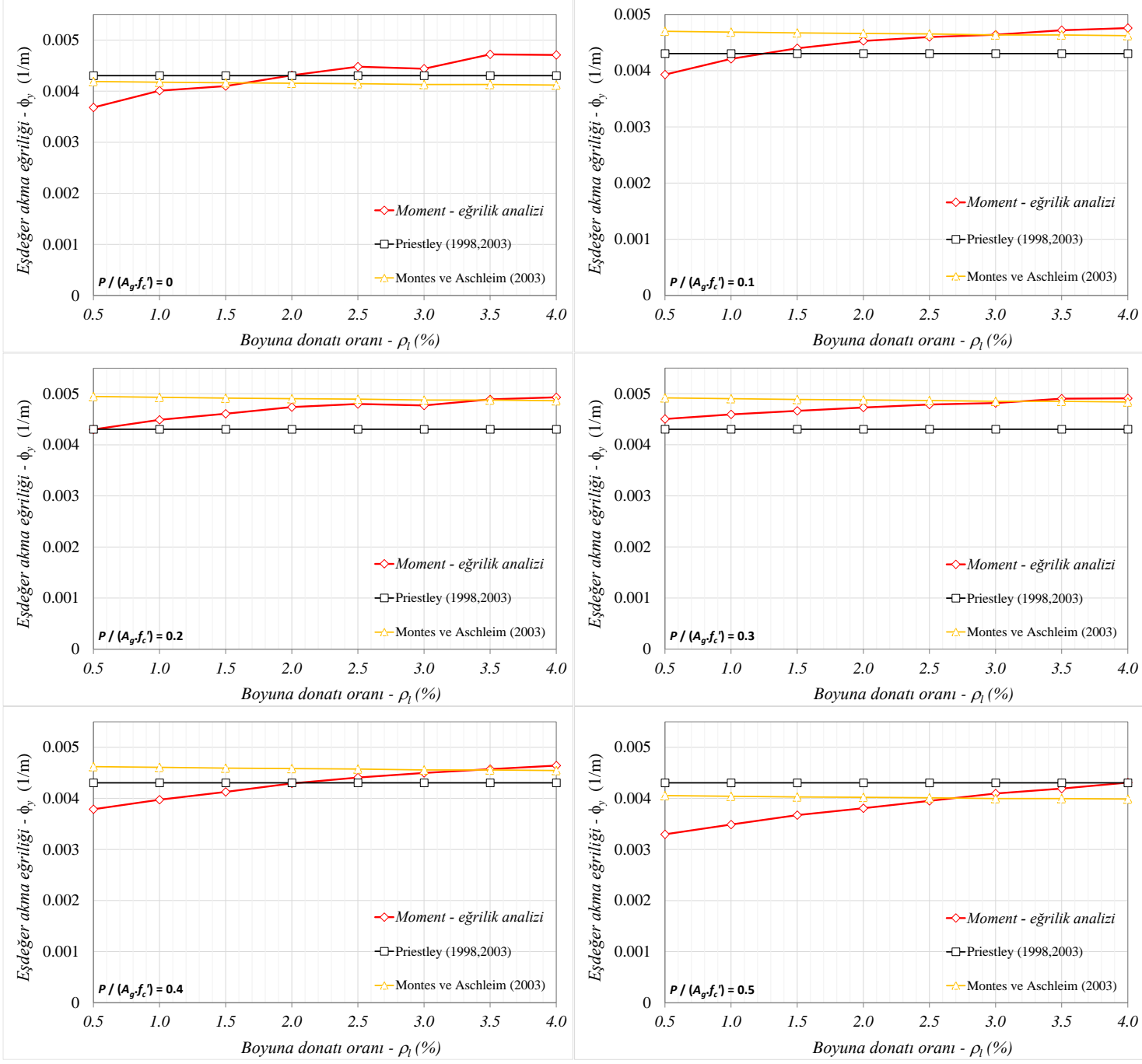

Şekil 7. Farklı boyuna donatı oranları için akma eğriliklerinin karşılaştırılması.

Eşdeğer akma eğrilikleri için (2a) bağıntısı kullanıldığında, düşük donatı oranlarında (özellikle $\rho_{l}=\% 0.5$ ve 1.0 ) hesaplanan akma eğrilikleri normal kuvvetin her düzeyinde bir 
miktar fazladır. Buna karşın, donatı oranı arttıkça akma eğriliklerine ait farkların azalan bir eğilim gösterdiği ve moment - eğrilik analizlerinden elde edilenlerle uyumlu hale geldiği görülmüştür (Şekil 7). $P / A_{g} f_{c}^{\prime} \leq 0.3$ için rölatif farklar $-\% 12.5 \sim+\% 19.7$ arasında değişmesine karşın, farklı donatı oranlarına ait ortalama hata \%2.3 düzeyindedir. $P / A_{g} f_{c}{ }^{\prime}=0.4$ ve 0.5 düzeyleri için ise ortalama rölatif farklar, sırasıly, $+\% 7.3$ ve $+\% 5.1$ oranlarındadır.

\subsubsection{Beton basınç dayanımındaki değişim bakımından sonuçların irdelenmesi}

Kolon enkesitlerine ait eşdeğer akma eğriliklerinin beton basınç dayanımı $\left(f_{c}^{\prime}=20-60\right.$ $\mathrm{MPa}$ ) ile değişimleri farklı normal kuvvet düzeyleri için Şekil 8'de verilmiştir. Moment - eğrilik analizleri sonucunda, $P / A_{g} f_{c}^{\prime} \leq 0.3$ düzeyine kadar beton basınç dayanımındaki artışın akma eğriliği üzerindeki etkisi çok küçük iken $(<\% 10)$, beton ezilmesinin hakim olduğu $P / A_{g} f_{c}^{\prime}>0.3$ düzeyleri için basınç dayanımı arttıkça eğrilik değerleri hızla azalmaktadır (Şekil 8). Eşdeğer akma eğriliklerinin pratik hesabı için literatürde önerilen bağıntılarda, beton basınç dayanımına ait etkilerin ihmal edildiği söylenebilir. İlgili bağıntılara ait sonuçlar incelendiğinde;

(1a) bağıntısından elde edilen akma eğriliklerinin, $P / A_{g} f_{c}^{\prime} \leq 0.3$ düzeyleri için daha az sonuç verdiği $(-\% 14.1 \sim+\% 1.2)$ ve beton basınç dayanımı arttıkça moment - eğrilik analiz sonuçlarına yakın hale geldiği belirlenmiştir (Şekil 8). Bu bölgede, kolon enkesitlerine ait akma eğrilikleri ortalama $\approx \% 6.5$ hata oranı ile belirlenebilmektedir. Normal kuvvetin ilerleyen düzeyleri için akma eğriliklerine ait rölatif farklar, basınç dayanımına bağlı olarak artan yöne geçmektedir. $P / A_{g} f_{c}{ }^{\prime}=0.4$ ve 0.5 için hesaplanan rölatif farklar, sırasıyla, $-\% 11.3 \sim+\% 12.5,-\% 6.7 \sim+\% 29.1$ arasında değişmekle birlikte, ortalama hata oranları $\% 0.2$ ve \%11 düzeylerindedir. İlgili bağıntıya ait en büyük fark, normal kuvvet düzeyinin ve beton basınç dayanımının en büyük olduğu kolon enkesitinde elde edilmiştir.

$P / A_{g} f_{c}^{\prime} \leq 0.3$ düzeylerinde (2a) bağıntısı kullanılarak her beton basınç dayanımı için hesaplanan eşdeğer akma eğriliklerinin moment - eğrilik analizlerinden elde edilenlerle oldukça uyumlu olduğu görülmüştür (Şekil 8). Bu düzeylerde, ilgili yaklaşım basınç dayanımı arttıkça bir miktar fazla sonuç vermekle birlikte, en büyük rölatif farkın $\approx \% 10$ olduğu söylenebilir. Beton ezilmesinin hakim olduğu daha yüksek normal kuvvet düzeylerinde $\left(P / A_{g} f_{c}^{\prime}>0.3\right)$, basınç dayanımındaki artışla birlikte hesaplanan farklar hızla yükselmektedir (Şekil 8). Elde edilen sonuçlara ait rölatif farklar $P / A_{g} f_{c}^{\prime}=0.4$ ve 0.5 için sirasıyla, $-\% 5.7 \sim+\% 19.6$ ve $-\% 12.9 \sim+\% 20.5$ arasında değişmekle birlikte, ortalama hata oranları \%6.1 ve \%3.5 düzeyindedir. Bu yaklaşım için en büyük rölatif fark, (1a) bağıntısında olduğu gibi normal kuvvet düzeyinin ve beton basınç dayanımının en büyük olduğu kolonda elde edilmiştir. 

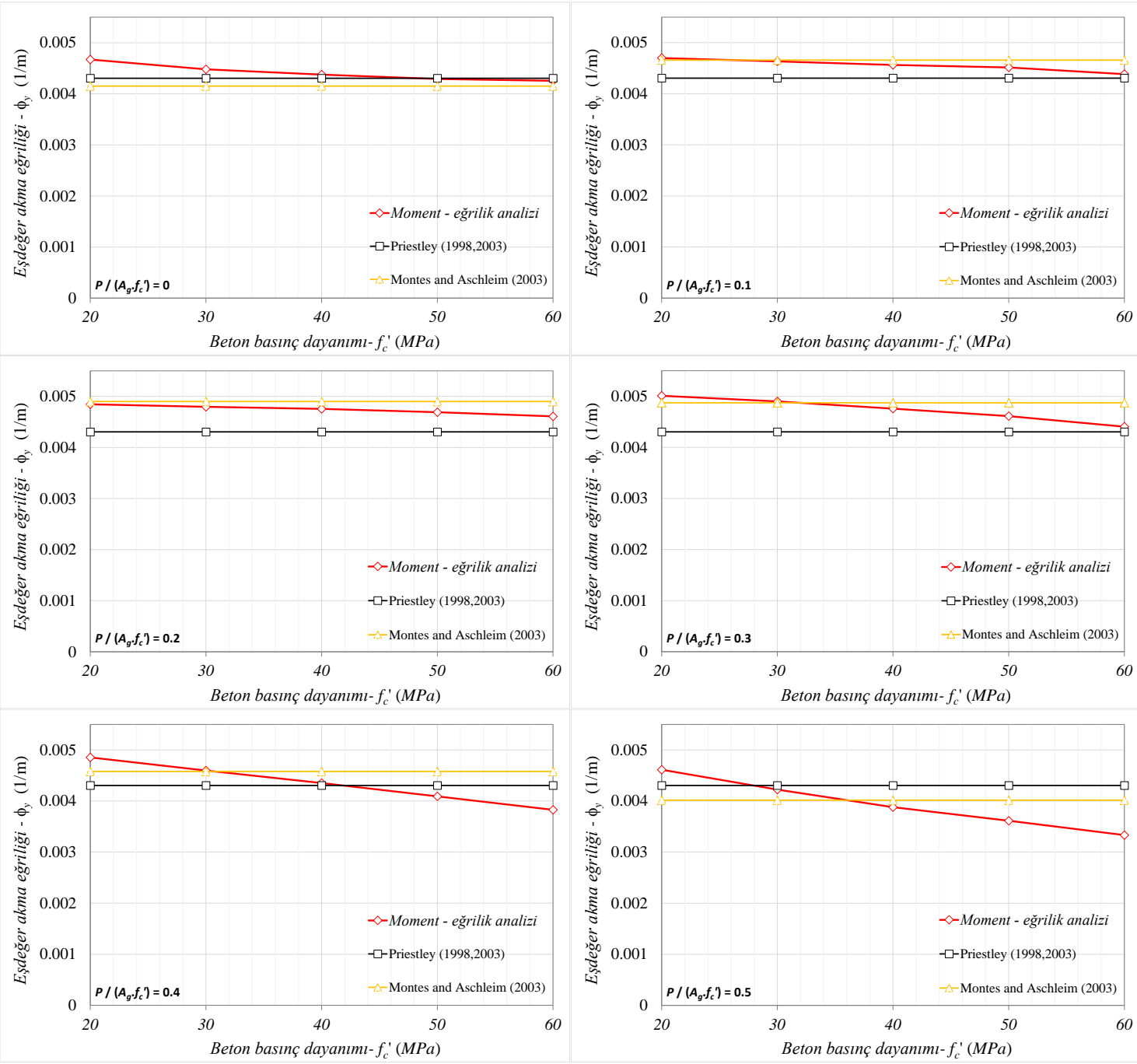

Şekil 8. Farklı beton basınç dayanımları için akma eğriliklerinin karşılaştırılması.

\section{Sonuçlar}

$\mathrm{Bu}$ çalışmada, betonarme kolonların eşdeğer akma eğrilikleri için literatürde önerilen pratik yaklaşımların geçerliliği kare enkesitler üzerinde incelenmiştir. Çalışma kapsamında, donatı akma dayanımı sabit tutularak enkesit boyutu, normal kuvvet düzeyi, boyuna donatı oranı ve beton basınç dayanımının parametrik olarak değiştirildiği 1500'ün üzerindeki hesap modeli için moment - eğrilik analizleri yapılmıştır. Daha sonra, ilgili bağıntıların hangi oranda doğru sonuç verdiği moment - eğrilik analiz sonuçları referans alınarak değerlendirilmiştir. Çalışma kapsamında yapılan varsayımlar altında elde edilen başlıca sonuçlar aşağıda sunulmuştur.

- Çalışma kapsamında birçok parametrenin sistematik olarak değiştirildiği kolon enkesitleri üzerinde yapılan moment - eğrilik analizleri sonucunda, enkesit yüksekliği ve normal kuvvet düzeyindeki değişimlerin eşdeğer akma eğriliği üzerinde belirleyici etkisinin olduğu görülmüştür. Akma eğriliklerinin belirlenmesinde normal kuvvetin düzeyine bağlı olarak, $P / A_{g} f_{c}{ }^{\prime}<0.3$ için donatı çeliğinin akması, $P / A_{g} f_{c}{ }^{\prime}=0.3$ için donatı çeliğinin akması ve/veya betonun ezilmesi, $P / A_{g} f_{c}^{\prime}>0.3$ için ise betonun ezilmesi hakim olmuştur. Akma eğriliği üzerinde boyuna donatı oranı ve beton basınç 
dayanımının bağımsız etkileri sınırlı iken, normal kuvvet düzeyi ile birlikte olan birleşik etkileri bu parametreleri önemli hale getirmektedir.

- Priestley tarafından önerilen bağıntı, her enkesit boyutunda birbirine yakın rölatif farklar ile akma eğriliklerini belirlemekle birlikte, normal kuvvet düzeyine bağlı olarak oluşan bu farkların eşit oranda azaldığ 1 ya da arttığ görülmüştür. $P / A_{g} f_{c}{ }^{\prime} \leq 0.3$ için akma eğrilikleri -\%14.1'ye ulaşan oranlarda daha az iken, $P / A_{g} f_{c}^{\prime}>0.3$ düzeylerinde rölatif farklar artan yöne geçerek $+\% 13.8$ 'a ulaşabilmektedir. Bununla birlikte, farklı donatı oranları için hesaplanan akma eğrilikleri, $P / A_{g} f_{c}^{\prime} \leq 0.3$ için daha az iken $\left(\rho_{1}=\% 0.5\right.$ ve 1.0 dişında), $P / A_{g} f_{c}{ }^{\prime}>0.3$ düzeylerinde rölatif farkların $+\% 29$ 'a ulaşabildiği belirlenmiştir. Bu bağıntı kullanılarak hesaplanan akma eğriliklerinin, $P / A_{g} f_{c}{ }^{\prime} \leq 0.3$ için daha az sonuç verdiği ve beton basınç dayanımı arttıkça moment eğrilik analiz sonuçlarına yaklaştığı belirlenmiştir. $P / A_{g} f_{c}^{\prime}>0.3$ için ise, akma eğriliklerine ait farklar basınç dayanımına bağlı olarak $\approx \% 29$ 'a ulaşabilmektedir.

- Montes ve Ashleim tarafından önerilen bağıntı, gözönüne alınan her normal kuvvet düzeyi ve enkesit yüksekliği için eşdeğer akma eğriliklerini oldukça iyi belirlemektedir. Düşük donatı oranlarında (özellikle $\rho_{l}=\% 0.5$ ve 1.0 ) hesaplanan akma eğrilikleri normal kuvvetin her düzeyinde bir miktar daha fazladır. Buna karşın, donatı oranı arttıkça akma eğrilikleri moment - eğrilik analizlerinden elde edilenlerle uyumlu hale gelmiştir. $P / A_{g} f_{c}{ }^{\prime} \leq 0.3$ düzeylerinde, her beton basınç dayanımı için hesaplanan akma eğriliklerinin referans sonuçlarla oldukça uyumlu olduğu görülmüşsür. Buna karşın, $P / A_{g} f_{c}^{\prime}>0.3$ için basınç dayanımındaki artışla birlikte oluşan farkların hızla arttığı belirlenmiştir.

Betonarme elemanlara ait eşdeğer akma eğriliklerinin pratik hesabına yönelik olarak, enkesit boyutu ile donatı akma şekildeğiştirmesinin yanısıra, normal kuvvet düzeyinin boyuna donatı oranı ve beton basınç dayanımı ile birleşik etkilerinin gözönüne alınması, şekildeğiştirme esaslı süneklik taleplerinin daha gerçekçi belirlenmesine olanak sağlayacaktır.

\section{Kaynaklar}

[1] prEN 1998-1, Eurocode-8: Design of structures for earthquake resistance - Part 1: General rules, seismic actions and rules for buildings. European Committee for Standardization, Brussels, (2003).

[2] AASHTO, Recommended LRFD guidelines for the seismic design of highway bridges, American Association of State Highway and Transportation Officials, NCHRP 20-07 Task 193, Washington DC, (2006).

[3] FEMA 356, Prestandard and commentary for the seismic rehabilitation of buildings. Federal Emergency Management Agency, Washington, DC, (2000).

[4] ACI-318, Building code and requirements for structural concrete, American Concrete Institute, Farmington Hills, Michigan, (2011).

[5] Türkiye Bina Deprem Yönetmeliği, Deprem etkisi altında binaların tasarımı için esaslar, Afet ve Acil Durum Yönetimi Başkanlığı, Ankara, (2018).

[6] Biskinis, D. ve Fardis, M.N., Deformations of concrete members at yielding and ultimate under monotonic or cyclic loading (Including repaired and retrofitted members), University of Patras - Department of Civil Engineering, Report No: SEE 2009-01, Patras, (2009).

[7] Priestley, M.J.N., Performance-based seismic design, Proceedings of $\mathbf{1 2}^{\text {th }}$ World Conference on Earthquake Engineering, Paper No: 2831, Auckland, (2000). 
[8] Priestley, M.J.N., Myths and Fallacies in Earthquake Engineering, Revisited the Ninth Mallet Milne Lecture, IUSS Press, Pavia, (2003).

[9] Priestley, M.J.N., The Need for Displacement-Based Design and Analysis, (In: Pecker, A. (eds) Advanced Earthquake Engineering Analysis), CISM International Centre for Mechanical Sciences, 494, 121 - 132, (2007).

[10] Priestley, M.J.N., Calvi, G.M. ve Kowalsky, M.J., Displacement-based seismic design of concrete structures, $6^{\text {th }}$ National Conference on Earthquake Engineering, İstanbul, (2007).

[11] Priestley, M.J.N., Calvi, G.M. ve Kowalsky, M.J., Displacement-Based Seismic Design of Structures, IUSS Press, Pavia, (2007).

[12] Priestley, M.J.N. ve Kowalsky, M.J., Aspects of drift and ductility capacity of rectangular cantilever structural walls, Bulletin of NZSEE, 31, 6, 73-85, (1998).

[13] Priestley, M.J.N., Brief comments on elastic flexibility of reinforced concrete frames and significance to seismic design, Bulletin of NZSEE, 31, 4, 246 - 259, (1998).

[14] Montes, E.H. ve Aschleim, M., Estimates of yield curvature for the design of reinforced concrete columns, Magazine of Concrete Research, 55, 4, 373 - 383, (2003).

[15] Tjhin, T.N., Aschleim, M.A. ve Wallace, J.W., Yield displacement estimates for displacement-based seismic design of ductile reinforced concrete structural wall buildings, $13^{\text {th }}$ World Conference on Earthquake Engineering, Paper No: 1035, Vancouver, (2004).

[16] Mander, J.B., Priestley, M.J.N. ve Park, R., Theoretical stress-strain model for confined concrete, Journal of Structural Engineering, 114, 8, 1804 - 1826, (1988).

[17] Mander, J.B., Priestley, M.J.N. ve Park, R., Observed stress-strain model of confined concrete, Journal of Structural Engineering, 114, 8, 1827 - 1849, (1988).

[18] King, D.J., Priestley, M.J.N. ve Park, P., Computer programs for concrete column design, University of Canterbury - Department of Civil Engineering, Research Report: 86/12, Christchurch, (1986).

[19] Montejo, L.A. ve Kowalsky, M.J., CUMBIA - Set of codes for the analysis of reinforced concrete members, North Carolina State University - Constructed Facilities Laboratory, Technical Report: IS-07-01, Raleigh, NC, (2007). 